\title{
6
}

\section{Development of a Basement Flooding Remediation Strategy}

\author{
Kevin Brown and Christine Hill
}

While sanitary sewer systems are designed to convey a certain amount of wet weather flow, excessive rainfall-derived infiltration and inflow (RDI/I) can cause sewer surcharging and basement flooding. Excessive RDI/I tends to become more of a problem as collection systems age, since groundwater can enter the sewer through cracks in manholes or the pipes themselves. In addition, stormwater runoff can enter sanitary sewer systems through foundation drains, roof downspouts, or catchbasins that are inadvertently or deliberately connected to the sanitary sewer pipes.

Municipalities own and maintain the sewer systems, and they have a certain obligation to residents and property owners who are served by these systems to minimize the risk of basement flooding as a result of rainfall events. Therefore, as the sewers age or new development or land use changes occur, municipalities should implement programs to reduce the risk of basement flooding.

This chapter presents a generic process that can be used to develop a basement flooding remediation strategy. The process is divided into five main steps, and is designed to be developed in conjunction with a stormwater management model (SWMM) such as EPA SWMM, or the many commercially-developed graphical user interfaces that have been built around it (PCSWMM, XP-SWMM, MIKE SWMM, etc). A case study is included as an example of how the process was applied as part of a recent project.

Brown, K. and C. Hill. 2003. "Development of a Basement Flooding Remediation Strategy." Journal of Water Management Modeling R215-06. doi: 10.14796/JWMM.R215-06.

(C) CHI 2003 www.chijournal.org ISSN: 2292-6062 (Formerly in Practical Modeling of Urban Water Systems. ISBN: 0-9683681-7-4) 


\subsection{Strategy Development Process}

The process is briefly described step-by-step, and a case study follows that exemplifies how the generic process can be applied to a specific scenario.

\subsubsection{Step 1 - Definition of Goals}

The first step in the process is to place the basement flooding strategy in the appropriate administrative context. Often, this type of project is reactionary, where a severe storm event triggered basement flooding in several homes. When addressing this type of issue, it is important to consider the municipality's drainage goals and design guidelines. It is also important to consider capital works projects that the municipality might already be planning. Cost savings can be realized if collection system modifications can be made under streets that are already scheduled for upgrades or reconstruction.

\subsubsection{Step 2 - Data Collection}

The next step in the exercise is to determine what data are available that might be useful in the development of a strategy. This includes, but is not limited to, the following:

- sewer flow, level and velocity data,

- rainfall records,

- record drawings of sewer pipes (plan and profile),

- basement flooding inspection reports,

- manhole inspection reports,

- closed-circuit television (CCTV) inspection reports,

- smoke- and/or dye-testing results,

- historical sewer connection by-laws,

- previously-developed collection system models and results, and

- Geographical Information System (GIS) data (which may include any of the above).

Each of the above items is discussed below in greater detail below.

\section{Sewer Flow, Level and Velocity Data}

Measured sewer flow, level and velocity data are of the utmost importance for quantifying the degree of surcharging in sewer systems, since these data provide the engineering basis for quantifying flooding problems. Unfortunately, these data are often not available in the critical reaches of the system when the 
strategy development begins. A strategy can still be developed without this data, however.

\section{Rainfall Records}

Perhaps more important than sewer flow data are rainfall records. While there are ways of getting around missing flow data (these will be discussed later), it is very difficult to develop a basement flooding remediation strategy without rainfall records. Excess flows in the sewers are typically caused by inflow and infiltration, which are both rainfall-driven. Without accurate rainfall data, it is almost impossible to quantify the RDI/I component of the sewer flow.

\section{Record Drawings of Sewer Pipes}

Plan/profile drawings provide the sewer profile, street centreline elevations, and sometimes basement elevations. This data can be quite useful when comparing computed hydraulic grade line (HGL) elevations with known flooding depths.

\section{Basement Flooding Inspection Reports}

In response to basement flooding complaints, municipal inspectors typically complete basement flooding inspection reports. While the exact information contained in these forms varies between municipalities, they will usually include the maximum depth of flooding (as reported by the resident), the nature of the sewage in the basement (storm or sanitary), and often an estimate of how deep the finished floor elevation is below grade. Inspectors will sometimes examine nearby manholes for evidence of sewer surcharging, and report their findings in these reports.

\section{Manhole Inspection Reports}

While manholes are sometimes inspected when flooded basements are reported, some municipalities also inspect manholes on a regular basis (e.g., annually). These inspection programs are aimed at identifying structural deficiencies, which can lead to excessive RDI/I into the sewer system.

\section{CCTV Inspection Reports}

Many municipalities also inspect sewers on a regular basis, particularly in areas where they are known to be subject to surcharging. These reports provide an indication of both the structural and service conditions of the sewer pipes. The structural condition rating will indicate if there are sags and cracks in the pipes, and the degree of infiltration into the pipes will be recorded if it is occurring at 
the time of the inspection. The service rating indicates the ability of the pipe to convey flow, and will indicate if there are build-ups of calcite or debris within the pipes.

Often, the structural and service condition ratings are represented as numbers ranging from 1 (excellent) to 5 (poor) (WRC, 1990). Whenever possible, the detailed reports should be obtained, as these will contain a listing of the specific deficiencies identified through the inspection.

\section{Smoke- and Dye-Testing Results}

Municipalities will often conduct smoke- and/or dye-testing in an effort to identify homes that have their foundation drains or roof downspouts connected to the sanitary sewer system. While foundation drain or downspout connection was a common construction practice in the past, many municipalities have passed by-laws prohibiting this practice, and have also instituted voluntary and/ or mandatory disconnection programs. Connected foundation drains and roof downspouts can cause severe surcharging of sanitary and combined sewers, so these should be accounted for when preparing a basement flooding remediation strategy.

If the smoke- or dye-testing programs are fairly dated, then there may be some discrepancies between the municipality's database and what exists. Homeowners or residents have been known to reconnect roof drains as an alternative to having them discharge to (and potentially saturate) their yards, as it is a fairly simple procedure. Reconnecting foundation drains involves significant excavation, and is therefore not as common.

\section{Historical Sewer Connection By-Laws}

When smoke- and dye-testing results are not available, it is possible to determine whether it is likely that homes do have one or both of their foundation drains and roof downspouts connected to the sanitary sewer based on the date of construction of the home. If the municipality has passed by-laws regarding these drains, then a simple cross-referencing will indicate which homes are likely to be connected to municipal sewers.

\section{Previous Modeling Reports}

While previous modeling work can provide very detailed information about a specific sewershed, the models can also be misleading. These models need to be carefully reviewed to develop an understanding of whether they can be applied to estimate the risk of basement flooding. The limitations of the previous 
model calibration need to be carefully considered. In addition, previous models may no longer represent the existing system.

\section{GIS Data}

Many municipalities are building GIS databases, and much of the data listed above may now be available in various map-based formats.

\subsubsection{Step 3 - Collection System Model Development}

A stormwater management model can be an extremely useful tool in developing a basement flooding remediation strategy. When flow data indicate the presence of RDI/I, a SWM model can be used to corroborate measured results by simulating the inputs into the sewers and routing them through the modeled pipe network.

Setting up the collection system is a fairly straightforward exercise, as physical pipe data is usually readily available. Care must be taken when assigning roughness factors for the pipe sections, however, as these can have a fairly significant impact on the pipe capacities. The as-built pipe diameters may no longer be accurate if the pipes are quite old, as they may have deformed over time. Also, presence of debris or calcite build-up might reduce the crosssectional area available to flow, which could lead to basement flooding. These factors should be taken into account when modeling the pipe network if possible, and CCTV inspection reports can provide the required details.

\subsubsection{Step 4 - Inclusion of Known Flow Sources and Initial Calibration}

If measured flow data are available, then typical dry-weather flow rates can be determined and included in the model. If data are not available, then dry-weather flows will need to be approximated based on land use and appropriate flow generation rates. Municipal sewer design guidelines generally contain this information. If these guidelines are not available, typical values might be available from the province or state's environment ministry (MOE, 1985).

Next, the known inflow sources should be identified and included in the model. If smoke- or dye-testing results indicate that certain foundation drains and/or roof downspouts are connected to the municipal system, then these can be applied to the model as point sources. GIS data (or aerial photos if appropriate GIS data are not available) can be useful in determining the roof areas that will contribute flows to the pipes through connected downspouts. The total flow 
volume contributed by connected roof leaders will typically be equal to the roof area multiplied by the rainfall depth. Approximating the impact of footing drains is a more difficult task, as it is dependant on soil conditions and construction practices. The response generated by both of these sources should be reasonably fast; roof leaders can convey flow to sewers almost instantaneously, and footing drains typically within about 15 minutes.

If the streets were known to be flooded during the flood event, then it is possible that stormwater was entering the sewer system through the manhole covers. Street flooding may be indicated on the basement flooding inspection reports, and pick holes in manhole covers may contribute flows to the system. Assuming there are two $25 \mathrm{~mm}$ by $25 \mathrm{~mm}$ ( 1 inch by 1 inch) openings in a manhole cover, standard orifice equations indicate that each submerged manhole could allow $1 \mathrm{~L} / \mathrm{s}$ to enter the sewer system under a depth of submergence of $15 \mathrm{~cm}$ ( 6 inches).

Once the known sources are accounted for, the model may be calibrated to peak flow rate and total wet weather volume using all available information. However, sometimes it is difficult to calibrate the model at this stage without first quantifying unidentified flow sources, as discussed next.

\subsubsection{Step 5 - Inclusion of Unidentified Flow Sources and Re-Calibration}

If the attempt at calibrating the model in Step 4 failed to match the observed peak flow rate or total wet-weather volume, then it is likely that there are some unidentified sources that are contributing flows to the sewers. Assuming the measured flow and rainfall data are valid and the SWM model representation is appropriate, some of the potential unidentified flow sources are:

- additional roof downspouts that were not previously identified,

- additional foundation drains that were not previously identified,

- groundwater and rainfall-derived infiltration into private sewer laterals,

- groundwater and rainfall-derived infiltration into municipal sewers,

- groundwater and rainfall-derived infiltration through faulty manhole gaskets, and

- transfer of flow from municipal storm sewers to municipal sanitary sewers (cross-connections).

Allowances for these types of sources can be included in a SWM model as runoff elements, and the size and number of these additional elements can be modified such that model calibration can be achieved. A good calibration will 
match both the peak runoff rate and the total runoff volume to within $15 \%$ of their respective measured values. It is important to recognise that these are not the actual flow sources, they are potential flow sources. Additional field inspections and data collection will be required to confirm these sources.

\subsubsection{Step 6 - Assessment of Remediation Options and Strategy Development}

Once a reasonable model calibration has been achieved, it is possible to run various scenarios in order to develop a list of potential remediation options. These will likely not be final solutions, as there are a number of assumptions inherent to this entire process that need to be verified. Nevertheless, it is possible to assess whether various remediation options are expected to be successful or not. For example, questions that can be asked are:

- If the pipes are known to be in poor condition, will cleaning them affect the hydraulic performance (e.g. lower the pipe roughness, or restore the pipe diameter closer to the as-built value)?

- If it appears that there are hydraulic bottlenecks in the system, will replacing these with larger-diameter pipes have any effect?

- Can known inflow sources (e.g. connected roof downspouts and foundation drains) be reduced? If so, will that have a significant impact on reducing the amount of flooding in the system?

- If the calibration process indicated that there are a number of unidentified flow sources, what are they likely to be, and can they be reduced? If so, will that have a significant impact on reducing the amount of flooding in the system?

- Will system storage (either on-line or off-line) be required to keep HGL elevations below finished basement elevations?

Once the list of potential remediation options is compiled, it is possible to rank the options based on the option's cost and expected benefit. Pipe cleaning, for example, is much less expensive than constructing additional storage; if there is a chance that it might sufficiently reduce the flooding risk, then it should be considered before additional storage.

Flow monitoring and model updating should be included as part of all remediation strategies. If recent flow data are not available, then data should be collected before any strategies are implemented. That way, the success of the various strategies can be evaluated by comparing the wet-weather response before and after the strategy has been implemented. 


\subsection{Case Study - Ontario, Canada}

In May 2000, part of the province of Ontario experienced a severe storm having a return period of about 25 years. In one municipality, this event caused occurrences of basement flooding across the city. XCG Consultants Ltd was retained by the city to develop a basement flooding remediation strategy to identify and address shortcomings in the collection system that contributed to the flooding.

\subsubsection{Definition of Goals}

The specific objective of this project was not to determine the exact causes of the basement flooding, rather it was to identify potential or likely causes, and to develop a program which the city could follow in order to confirm the causes, and reduce or eliminate them. As most of the basement flooding occurrences were related to the sanitary sewer system, the scope of the project was confined to that system only. The results of this study would ideally narrow the scope of the remediation process, as it would indicate the likely sources of the basement flooding problems, while eliminating other potential sources.

As a first step in the process, a series of eleven hydraulically isolated basement flooding clusters were identified. Basement flooding in each cluster area was identified as being a result of surcharging in the local sewers, based on an initial review of the system and the basement flooding complaints.

\subsubsection{Data Collection}

Following the methodology outlined above, a detailed review of the available data was performed next. The results of this review are presented in Table 6.1.

Since sewer flow data were very limited, it was only possible to calibrate the model to measured flows in the cluster area where data from three events was available. In the ten remaining cluster areas, the model had to be calibrated to approximate HGL levels, which were recorded in the basement flooding inspection reports.

\subsubsection{Pipe Network Model Development}

Extensive sewer information was available, so it was possible to build a very detailed model of the collection system. Along the streets where flooding was reported, each pipe was modeled. In areas sufficiently upstream and downstream 
Table 6.1 Data availability for the case study.

\begin{tabular}{|c|c|}
\hline Data & Availability \\
\hline \multirow[t]{3}{*}{$\begin{array}{l}\text { Sewer Flow, Level and } \\
\text { Velocity Data }\end{array}$} & $\begin{array}{l}-3 \text { events plus the storm that caused the flooding in one } \\
\text { cluster area. }\end{array}$ \\
\hline & $\begin{array}{l}-1 \text { event plus the storm that caused the flooding in } \\
\text { another cluster area. }\end{array}$ \\
\hline & -Fairly extensive data from the trunk sewers. \\
\hline Rainfall Records & -Fairly extensive and reliable rain gauge network. \\
\hline $\begin{array}{l}\text { Record Drawings of } \\
\text { Sewer Pipes }\end{array}$ & -Available for all 11 cluster areas. \\
\hline $\begin{array}{l}\text { Basement Flooding } \\
\text { Inspection Reports }\end{array}$ & -Available for almost all flooding incidences. \\
\hline $\begin{array}{l}\text { Manhole Inspection } \\
\text { Reports }\end{array}$ & $\begin{array}{l}\text {-Not available, except for some cases where manholes } \\
\text { were inspected following flooding complaints. }\end{array}$ \\
\hline $\begin{array}{l}\text { CCTV Inspection } \\
\text { Reports }\end{array}$ & $\begin{array}{l}\text {-Available for most of the streets where several flooding } \\
\text { incidences were reported. }\end{array}$ \\
\hline Dye-Testing Results & $\begin{array}{l}\text {-Available for all clusters, though the results were } 10-15 \\
\text { years old. }\end{array}$ \\
\hline $\begin{array}{l}\text { Historical Sewer } \\
\text { Connection By-Laws }\end{array}$ & -In place, with the by-law dates available. \\
\hline $\begin{array}{l}\text { Previous SWMM } \\
\text { Models and Results }\end{array}$ & -Available for one cluster, but fairly old. \\
\hline \multirow[t]{3}{*}{ GIS Data } & -Land parcels \\
\hline & -Sewer information \\
\hline & -Building outlines, and date of construction \\
\hline
\end{tabular}

from these locations, some consecutive pipe sections were lumped together using a hydraulically equivalent pipe, if there were no significant changes in their slopes or diameters.

Each of the cluster areas was modeled all the way to the trunk sewer into which it discharged. Sewer flow data and anecdotal evidence suggested that the trunk sewers were flowing full. Consequently, the downstream boundary condition at each outfall into the trunk sewer was taken as the crown elevation of the trunk sewer when the model was used in an attempt to replicate the occurrences of basement flooding.

CCTV data from each of the cluster areas were analysed. Modeled pipe diameters were decreased from their as-built values where the CCTV inspection results indicated calcite or debris build-up. 


\subsubsection{Inclusion of Known Flow Sources and Initial Calibration}

Dry-weather flow data were available for two of the eleven cluster areas. When this data was analysed, it was found to be fairly consistent in terms of daily flow rates per residence (approximately $900 \mathrm{~L} / \mathrm{d}$ ). As all eleven clusters were mainly residential areas of similar dwelling unit densities, these flow generation rates were applied to the remaining nine clusters where no dry-weather flow data were available.

The municipality had previously implemented a mandatory roof downspout disconnection program, and dye-testing results indicated that few roof drains remained connected to the sanitary sewer. The roofs that were not disconnected were included in the model as point sources.

No such disconnection program had been implemented for foundation drains, so a number of homes remain connected to the sanitary sewer. Typically, entire neighbourhoods are connected to the same type of sewer (storm or sanitary), as the home construction dates are similar. The homes that are connected to the sanitary sewer were included in the model as point sources. An in-house model was developed to approximate the flows that would be collected by foundation drains, based on known soil types and construction practices. The model conceptualised the on-lot drainage system, consisting of

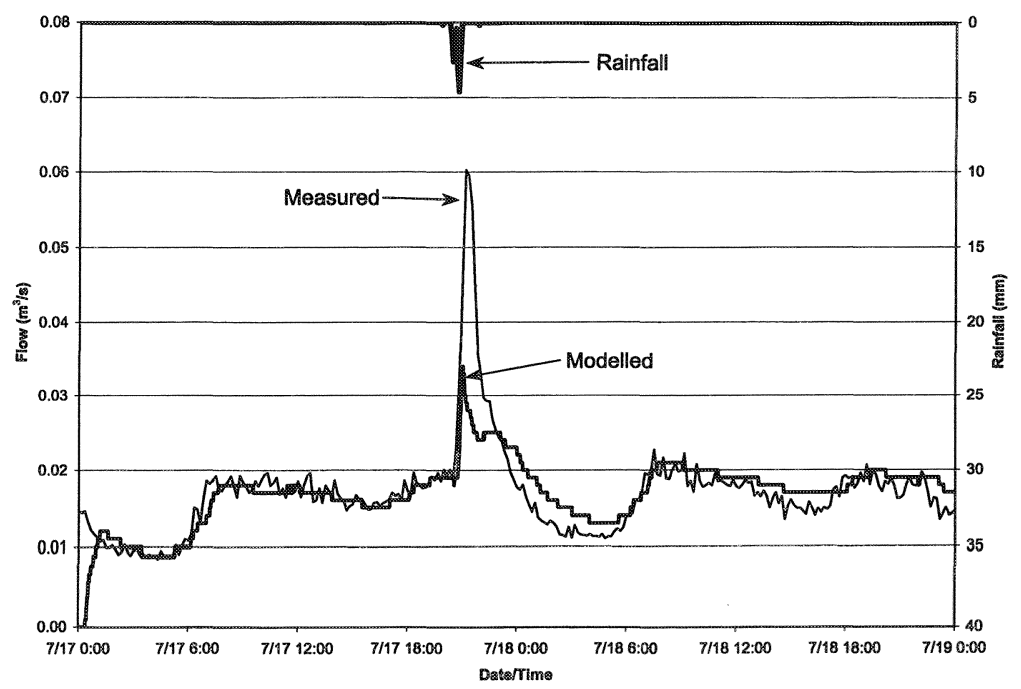

Figure 6.1 Rain and flow hydrograph. 
a shallow soil element (representing a layer of topsoil over the entire property), a drain element (representing the typically well-drained soil adjacent to the foundation), and a native soil element (representing the undisturbed soil under the shallow soil element). Hydraulic conductivities for these elements were selected based on an understanding of the local soil conditions, and contributions to the foundation drain were calculated using groundwater flow equations.

As the sewer pipes in the cluster areas are all approximately $40 \mathrm{y}$ old, a slow runoff response was also included to approximate infiltration in these older pipes. This was further supported by CCTV inspection data that identified a number of infiltration sources. The infiltration assumption was applied systemwide, and not just in the specific locations where CCTV data were available.

Once these sources were included in the model, an attempt was made to calibrate the model for the two cluster areas where flow data were available. As expected, the model results fell short in both peak flow rate and total wet-weather volume, though the shape of the runoff hydrograph was very similar to the observed. An example of typical flow hydrographs from this early calibration stage of the analysis is provided in Figure 6.1.

\subsubsection{Inclusion of Unidentified Flow Sources and Re-Calibration}

In order to improve the model calibration shown in Figure 6.1, an additional catchment area was created, and the runoff parameters for this catchment were established such that the missing flow from the previous step was accounted for. A typical refined calibration curve is included in Figure 6.2. The flow generated from this additional catchment represents the sum of all unknown inflow sources upstream of the flow meter.

For the two areas where flow data were available, this additional flow was proportional to the size of the total catchment area. The additional catchments were then scaled appropriately (i.e. based on area) for each of the remaining nine cluster areas. These nine clusters were then further calibrated such that the modeled peak HGL elevations were consistent with the flooding depths recorded in the basement flooding inspection reports. A typical profile plot showing the street centreline, sewer pipes, basement depths, and reported and modeled flooding depths is provided in Figure 6.3.

Once a reasonable match was achieved for each of the cluster areas, the calibration of individual models was deemed to be acceptable for the purpose of assessing various remediation options. 


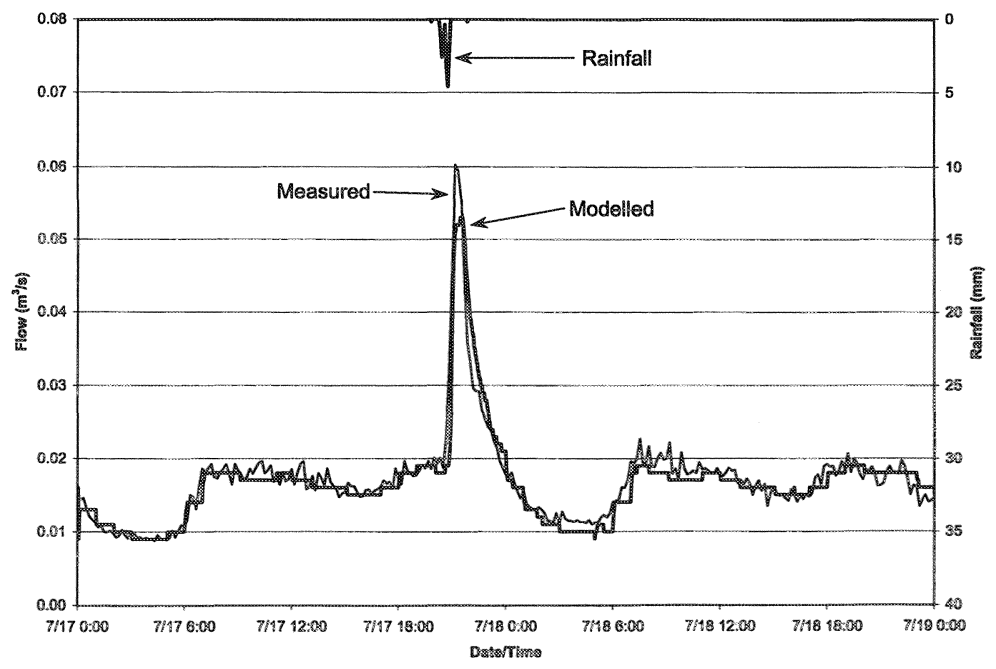

Figure 6.2 Calibrated hydrograph.

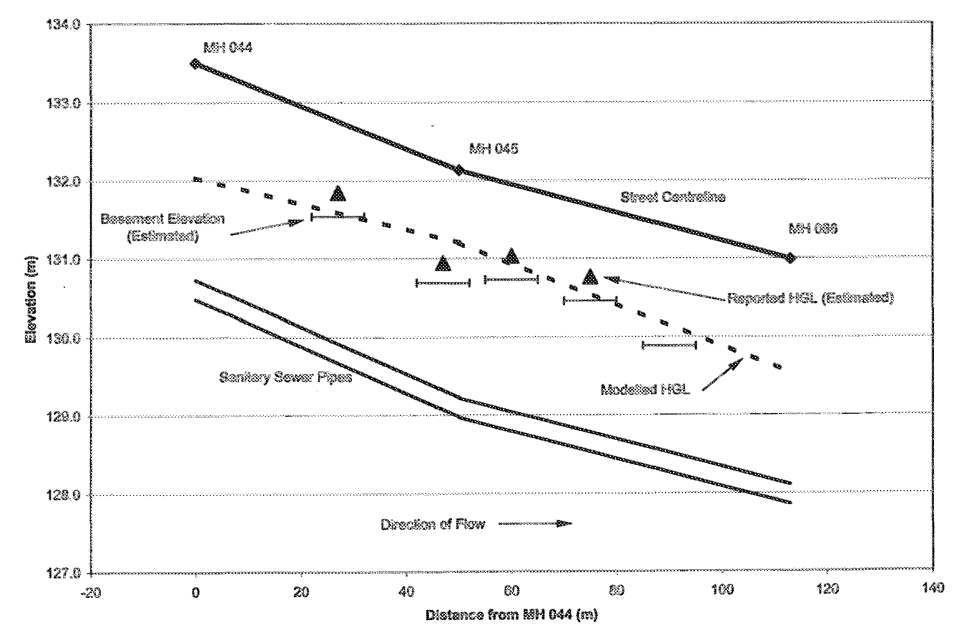

Figure 6.3 Typical profile.

\subsubsection{Assessment of Remediation Options}

A list of preferred remediation options was developed and prioritised through discussions with city staff. The remediation options considered are listed below in the preferred order of implementation: 


\section{Pipe Cleaning Program}

In order to assess the effectiveness of this program, the diameters of all modeled pipes were restored to their as-built values. This would simulate the removal of roots, debris, and calcite deposits.

\section{Inflow Source Disconnection}

While the municipal records suggested that there are only a few homes that still have roof downspouts or foundation drains connected to the sanitary sewers, model calibration indicated that there are potentially homes that have reconnected, and the municipality is not aware of them. The inflow source disconnection program would attempt to identify and reduce these sources, as well as other potential inflow sources.

Modeling results were generated based on the assumption that $10 \%$ of connected foundation drains, and one half of all other inflow sources could be eliminated. The foundation drain disconnection success rate is based on similar disconnection programs implemented by the municipality, and greater than $50 \%$ inflow source reductions have been achieved in other North American cities (McCormack, 2000). Fairly extensive flow monitoring would be required to identify the unknown inflow sources.

\section{Hydraulic Improvements}

If inflow source disconnection programs are not successful to the degree necessary, then hydraulic improvements should be considered. These would involve removing hydraulic bottlenecks from the system, and providing minor upgrades to the collection system. Widespread pipe replacement was not to be considered as part of this option. Rather, if single pipe sections at critical locations in the collection system were deemed to be undersized, then consideration would be given to increasing the conveyance capacity of the pipe.

\section{System Storage}

As a final option, additional system storage (either on-line or off-line) could be constructed to maintain peak HGL elevations within acceptable levels. In order to establish an upper limit on the cost of providing system storage, storage requirements were sized without consideration of RDI/I reduction programs under the assumption that these would not be effective in reducing peak wetweather flows in the collection system.

The assessment of the various remediation options included an evaluation of the effectiveness and cost of each option. Effectiveness was measured by 
the improvement in hydraulic performance as indicated by model results. The specific goals were to prevent pipe surcharging, and limit peak HGL levels to $1.8 \mathrm{~m}(6 \mathrm{ft})$ below grade for a 4-h design storm with a return period of $25 \mathrm{y}$.

\subsubsection{Strategy Development}

As the scope of this study was fairly broad and potential causes of basement flooding were still unconfirmed, the proposed remediation strategy had to broad enough to apply to all of the individual cluster areas, and flexible enough to be refined as additional data became available. The final remediation strategy is outlined in Figure 6.4.

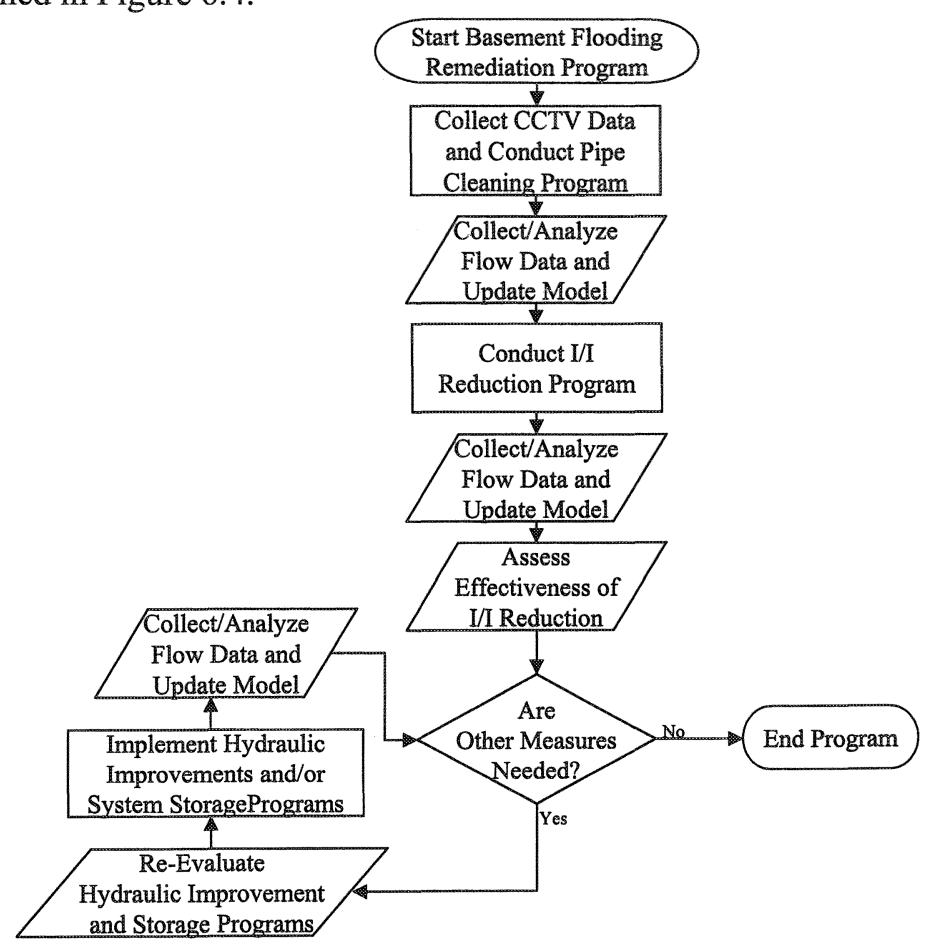

Figure 6.4 Remediation strategy.

Based on modeling results, the pipe cleaning programs are not expected to remove the flooding risks associated with a 25 -y design storm. Rather, they are intended to restore the pipe capacities to their design performance levels, which will be advantageous when implementing successive programs. The 
flow data collected during this time will also allow for refinement of the model, and provide a baseline against which future improvements can be evaluated.

Preliminary model calibration suggested that there were both known and unidentified inflow sources in all eleven cluster areas, and the RDI/I reduction program would attempt to identify and disconnect as many of them as possible. If the RDI/I reduction programs are successful to the extent anticipated, this should remove the basement flooding risk associated with a 25-y design storm for 8 of the 11 cluster areas. The flow data collected after these programs are completed will indicate whether that is the case. If this data suggests otherwise, then hydraulic improvements and/or system storage will be considered.

In the three cluster areas where the RDI/I reduction programs were not likely to be effective, the modeling results were further analysed to determine if there were bottlenecks in the systems that could be removed. Such a situation was discovered in one of the cluster areas, meaning that system storage would have to be considered in the other two.

System storage, both on-line and off-line, was considered a potential necessity in all 11 cluster areas. In two of the cluster areas, it would likely be required whether the RDI/I reduction programs were successful or not, and in the other nine cluster areas storage was considered in the event that the RDI/ I reduction programs were not successful. In all cases, an upper storage volume and cost were developed, and these will be re-evaluated once flow data reveals how successful the RDI/I reduction programs were. Once proposed improvements are designed and constructed, additional flow data should be collected to confirm whether this phase of the remediation strategy was successful. If not, then the model will be refined and additional improvements considered.

\subsection{Summary}

Once specific goals have been established, the development of a basement flooding remediation strategy should always begin with a thorough data collection and review process. There will surely be shortcomings in the amount of data that are immediately available, but in some cases this can be overcome by considering other sources. It is important to identify these data sources as early in the process as possible. If it is necessary to collect additional data before proceeding, then it should be done as early in the project as possible.

The next step is to use a SWM model to construct an accurate representation of the collection system. Plan/profile drawings will provide the as-built conditions, but these may no longer be appropriate for constructing a model 
representing the actual condition of the system. CCTV inspection data or knowledge of the system will provide guidance in this regard.

Next, the model must include a representation of known flow sources, and calibrated if possible. If additional flows are needed to reproduce the measured flow rates or known HGL elevations, then additional model catchments can be included to represent unidentified inflow sources.

The calibrated model can then be used to assess the effectiveness of various remediation options, and a final strategy developed. The remediation strategy should always include constant flow monitoring, and updating of the model at the completion of every step of the remediation process. Doing so will indicate whether individual programs were successful to the extent anticipated, and provide an opportunity to modify the overall strategy as necessary.

One of the advantages of developing a strategy such as the one presented in the case study is that it is possible to estimate a cost for each step of the remediation strategy. This will allow municipalities, which tend to have a fixed annual budget for collection system work, to anticipate future expenditures and prioritise improvements.

\section{References}

Haasen, J., Richert, B., and McMichael, R, 2000. Simple is Sometimes Best: City of Sarnia Basement Flooding/CSO Mitigation Plan. Conference Proceedings, 29th Annual WEAO Technical Symposium and OPCEA Exhibition.

McCormack, K.D., Bennett, B.D., and Spallasso, R.S., 2000. A Pilot Program for Removal of $\mathrm{I} / \mathrm{I}$ from Private Sources. Water Environment Federation Specialty Conference Paper.

Ontario Ministry of the Environment (MOE), 1985. Guidelines for the Design of Sanitary Sewage Systems. Published by MOE.

United States Environmental Protection Agency (USEPA), 1999. Combined Sewer Overflow Technology Fact Sheet: Inflow Reduction. Published by USEPA.

Water Environment Federation (WEF), 1999. Prevention and Control of Sewer

System Overflows, Manual of Practice FD-17. Published by WEF. pp.149-155 Water Research Centre (WRc), 1990. Sewerage Rehabilitation Manual. Published by WRc Inc. Vol II, pp 135-147.

XCG Consultants Ltd. 2001. City of Toronto Basement Flooding Remediation Strategy, Study Area 3 - Final Report. 